\title{
HYDROGELS BASED ON (DIMETHYLAMINO)ETHYLACRYLATE (DMAEA) AND N,N'- DIMETHYLACRYLAMIDE (NNDMAAM): SYNTHESIS, CHARACTERIZATION, AND SWELLING BEHAVIOR
}

\author{
S.AMALIA POOLEY*(l), BERNABÉ L. RIVAS ${ }^{(1)}$, GUADALUPE DEL C. PIZARRO(2). \\ (1) Polymer Department, Faculty of Chemistry, University of Concepción, Casilla 160-C, Concepción, Chile. \\ (2) Department of Chemistry, Technological Metropolitan University, J. P. Alessandri 1242, Santiago, Chile
}

(Received: July 12, 2012 - Accepted: October 12, 2012)

\begin{abstract}
Hydrogels of 2-(dimethylamino)ethylacrylate (DMAEA) with N,N'-dimethyl acrylamide (NNDMAAm) were synthesized by solution free-radical polymerization at different feed mol ratios. These copolymers were completely water-insoluble. Polymers were characterized by elemental analysis, FT-IR spectroscopy, thermogravimetric analysis (TGA), and scanning electron microscopy (SEM).

The monomer reactivity ratios were determined by Kelen-Tüdos method. According to that, the monomer reactivity ratios for poly(DMAEA-co-NNDMAAm) were $r_{1}=0.288\left(M_{1}=\right.$ DMAEA $)$ and $r_{2}=1.460\left(M_{2}=\right.$ NNDMAAm $),\left(r_{1} \times r_{2}=0.419\right)$.

Low critical solution temperatures (LCST) values of hydrogels are around $60^{\circ} \mathrm{C}$, which was significantly higher than that poly(NIPAAm) and increased with increasing of hydrophilic DMAEA unit content in the copolymers. The hydrogels achieved a water-absorption value of $188 \mathrm{~g}$ of water/g of dry polymer (xerogel) in distilled water. Effects of time, temperature, $\mathrm{pH}$, salt concentration, cross-linking concentration, and solvent polarity on the water absorption were studied. Experimental results indicated that the copolymer poly(DMAEA-co-NNDMAAm) with a feed mol ratio 2:1 presents the best swelling properties.
\end{abstract}

Key words: Hydrogels, radical polymerization, swelling, stimuli-sensitive polymers.

\section{INTRODUCTION}

Hydrogels are three-dimensional crosslinked hydrophilic polymeric structures that are able to swell in an aqueous environment ${ }^{[1-10]}$. Due to their high water content, low water contact angle, high permeability, and low friction coefficient, hydrogels are studied extensively as a replacement for soft tissue ${ }^{[4]}$.

Hydrogel is a class of polymeric material with the ability to hold a substantial amount of water, presenting a soft, rubbery-like consistency, and low interfacial tension parameters ${ }^{[3]}$. Product of a large amount of research during the last two decades, hydrogels are now recognized as a well established class of polymers with widespread applications in agriculture, medicine, food industry, biotechnology, environmental sciences, among others. The structural feature of these materials dominates its surface properties, permeselectivity and permeability, giving hydrogels with their unique, and interesting properties and the similarity of their physical properties to those of living tissue ${ }^{[11,12]}$.

Hydrogel properties mainly depend on the degree of crosslinking, the chemical composition of the polymeric chains, and the interaction of the network and surrounding liquids. Hydrophilicity or high water retention in hydrogels is attributed to the presence of hydrophilic groups, such as carboxylic acids, amides, alcohols and so on ${ }^{[5]}$.

In stimulus responsive hydrogels, the response of the functional group, depending on the type, changes according to the scale of external stimulus, such as $\mathrm{pH}$, temperature, and salt concentration. These environmental variables are always found in controlled drug delivery, immobilized enzyme reactors, and separation processes ${ }^{[11-15]}$.

The use of acrylic acid based hydrogels to concentrate environmental samples by absorbing excessive amounts of water for pesticide residue analysis is a unique application in environmental monitoring ${ }^{[16]}$.

The poly(N-isopropylacrylamide), poly(NIPA), exhibits a sharp phase transition in water. Poly(NIPAAm) has a lower phase transition temperature at around $32^{\circ} \mathrm{C}$. Several authors ${ }^{[11-15]}$ have studied the collapse temperature in poly(NIPAAm) hydrogels and reported that while incorporation of a hydrophilic comonomer leads to a higher LCST, incorporation of a hydrophobic monomer decreases the critical temperature Tc. The reason for this sharp phase transition is a good balance between hydrophilic and hydrophobic interactions in the polymer ${ }^{[17]}$. It undergoes a temperature induced collapse from an extended coil into a globule structure, a transition revealed on the macroscopic scale by a sudden decrease of the degree of swelling of poly(NIPAAm) gels ${ }^{[18-31]}$. Raising the temperature of an aqueous poly(NIPAAm) solution above the LCST causes a coil-to-globule transition, followed by a phase separation. This phase transition is accompanied by a release of water bound to the polymer chain, which is an endothermic process. In the literature, some methods for the detection of the LCST have been reported. Thus, light scattering to detect the coil-to-globule transition ${ }^{[23]}$, turbidimetric measurements to achieve phase transition ${ }^{[24]}$, or differential scanning calorimetry (DSC) to measure the transition heat ${ }^{[25]}$ have been reported. The proposed application of these polymers is their use in the preparation of thermosensitive polymers (microsystems). As these devices are employed in real environments, the copolymers will have temperatures far in excess of their LCSTs (typically ca. $30^{\circ} \mathrm{C}$ for poly(NIPAAm) ${ }^{[18]}$ in the course of their lifetimes. Thus, the thermal properties of the copolymers, especially the glass transition temperatures $(\mathrm{Tg})$ and the thermal decomposition were investigated

The network density of the polymeric gels is also an important factor that is responsible for controlled release of active molecules.

We have previously published ${ }^{[29-31]}$ the synthesis and swelling properties of hydrogels from functional vinyl monomers. These systems showed that the copolymers containing acrylic acid and acrylamide derivative moieties are very sensitive to stimulus as $\mathrm{pH}$, temperature, ionic strength, and copolymer composition.

The aim of this paper is synthesize copolymers of 2-(dimethylamino) ethylacrylate with $\mathrm{N}, \mathrm{N}^{\prime}$-dimethylacrylamide at different feed comonomer ratios with different amount of crosslinking reagent, and study the swelling effects of these hydrogel systems in twice distilled water at different $\mathrm{pH}$, temperature, time, and salt concentration.

\section{EXPERIMENTAL}

Materials

2-(dimethylamino)ethylacrylate (DMAEA;Aldrich) was purified by distillation at $64^{\circ} \mathrm{C}$ and $12 \mathrm{~mm} \mathrm{Hg}$. All the other reagents were used as received.

Preparation of poly[2-(dimethylamino)ethylacrylate-co-2-NNDMAAm], poly(DMAEA-co-NNDMAAm).

Crosslinked poly(DMAEA-co-NNDMAAm) hydrogels, containing $25,33,50,66$, and 75 mol- $\%$ of DMAEA were prepared by free radical solution polymerization. NNDMAAm was dissolved in water, DMAEA, $\mathrm{N}, \mathrm{N}$-methylene-bis-acrylamide, MBA, and ammonium persulfate, APS, as crosslinking and initiator reagents respectively were added in the above NNDMAAm solution, the reaction solution was heated and polymerized for 24 $\mathrm{h}$ at $70^{\circ} \mathrm{C}$ in a Teflon tube of $40 \mathrm{~mm}$ diameter. The product was cut into small discs $5 \mathrm{~mm}$ x $20 \mathrm{~mm}$, and vacuum dried until constant weight. Finally, the dried product was characterized and the swelling properties were determined.

The feed mole ratios of DMAEA and NNDMAAm are $1: 1 ; 1: 2 ; 2: 1$, $1: 3$, and 3:1. The total weight percentage of both monomers is $20 \%$. The mol percentage of the cross-linking compared with the monomers is $4 \%$. The mol percentage of the initiator compared with the monomers is $0.01 \%$.

Nevertheless, the crosslinking reagent is part of the polymer chain it was not considered to calculate the N/C ratio. It is due to the amount is low and it 
will not contribute significantly considering the experimental error.

\section{Hydrogel characterization}

The dried copolymers were ground to a suitably sized powder for FT-IR analysis. The FT-IR spectra of the copolymers were obtained with a Magna Nicolet IR-550 spectrometer.

The thermogravimetry analyses of the copolymers were obtained by using TGA (Polymer Laboratories, STA-625 thermobalance). Measurements of $5 \mathrm{mg}$ of dry samples were performed with a heating rate of $10{ }^{\circ} \mathrm{C} / \mathrm{min}$ from room temperature to $550^{\circ} \mathrm{C}$ under nitrogen atmosphere.

Copolymer morphology was examined with scanning electron microscopy (SEM) (Jeol, GSM-6380LV).

Swelling measurements

Sample of poly(DMAEA-co-NNDMAAm) $(0.5 \mathrm{~g})$ was immersed in $400 \mathrm{~mL}$ of distilled water for $12 \mathrm{~h}$ until equilibrium was reached at room temperature. The weight of the swollen gel was measured after the excess surface solution was removed by filter paper. Then, the swollen gel was weighed. The absorbency was calculated by using the following equation:

$$
\mathrm{Q}=\left(\mathrm{W}_{2}-\mathrm{W}_{1}\right) / \mathrm{W}_{1}
$$

Absorbency is expressed in grams of liquid retained in the gel per grams of dry copolymer. $\mathrm{W}_{2}$ and $\mathrm{W}_{1}$ are the weights of the swollen gel and the dry poly(DMAEA-co-NNDMAAm), respectively.

Effect of time, temperature, and $p H$ on absorbency

The methods were the same as used for the swelling measurement in twice distilled water, in saline solutions, and ethanol. The $\mathrm{pH}$ values of the solution were adjusted with $\mathrm{HCl}$ or $\mathrm{NaOH}$.

Water retention capacity

The swollen gels that reached equilibrium in water were drained in nylon bags for $1 \mathrm{~h}$, then, the gels and the bags were put into an oven and heated at constant temperature. To investigate the variation in their weight, they were weighed at $1 \mathrm{~h}$ intervals.

\section{RESULTS AND DISCUSSION}

Stimulus-responsive hydrogels change their volume and elasticity in response to a change in liquid phase properties, such as temperature, $\mathrm{pH}$, solvent composition, and ionic strength. Depending on the chemical composition of gels and liquid in experimental conditions the change in the swelling behavior can occur either continuously or non-continuously.

The relationship between the gels' swelling behavior and the copolymerization ratio were studied at different temperatures in solutions with various $\mathrm{pH}$. The transition temperature of the crosslinked gels changed according to the feed monomer ratio used in copolymerization. The $\mathrm{pH}$ value of the solution strongly affected the swelling ratio.

Synthesis and characterization

The yield for all copolymer systems was higher than that $90 \%$ (see Table 1). Hydrogels are transparent, smooth, and maintain their shape in the swollen state.

Table I. Experimental conditions of the copolymerization reaction and yield poly(DMAEA-co-NNDMAAm) 4 mol- $\%$ MBA /1 mol-\% PSA. MBA: $8.87 \times 10^{-4}$, PSA: $2.23 \times 10^{-4}$

\begin{tabular}{|c|c|c|c|c|}
\hline $\begin{array}{c}\text { Polymer } \\
\text { Sample } \\
\text { No }\end{array}$ & $\begin{array}{c}\text { Feed } \\
\text { monomer ratio } \\
\text { (in mol) }\end{array}$ & $\begin{array}{c}\text { [DMAEA }] \\
(\mathrm{mol})\end{array}$ & $\begin{array}{c}\text { [NNDMAAm] } \\
(\mathrm{mol})\end{array}$ & $\begin{array}{c}\text { Yield } \\
(\%, \mathrm{w} / \mathrm{w})\end{array}$ \\
\hline 1 & $1: 1$ & 0.0111 & 0.0110 & 90.7 \\
\hline 2 & $1: 2$ & 0.0074 & 0.0149 & 92.6 \\
\hline 3 & $2: 1$ & 0.0147 & 0.0074 & 97.0 \\
\hline 4 & $1: 3$ & 0.0055 & 0.0166 & 90.8 \\
\hline 5 & $3: 1$ & 0.0166 & 0.0055 & 91.1 \\
\hline
\end{tabular}

Figure 1 shows the FT-IR spectra of the copolymers poly(DMAEA-coNNDMAAm), 1:1; 1:2, 2:1, 1:3, and 3:1 with 4 mol-\% of MBA. The spectra show the typical absorption bands of both comonomers and the crosslinking reagent. Among the most characteristic absorption bands are the following (in $\left.\mathrm{cm}^{-1}\right): 3409(\mathrm{~N}-\mathrm{H}) ; 2947,2810$ (C-H stretching, aliphat.); $1601(\mathrm{C}=\mathrm{O}$ vibration of the ester group); 1063 (N-H deformation of amide group).

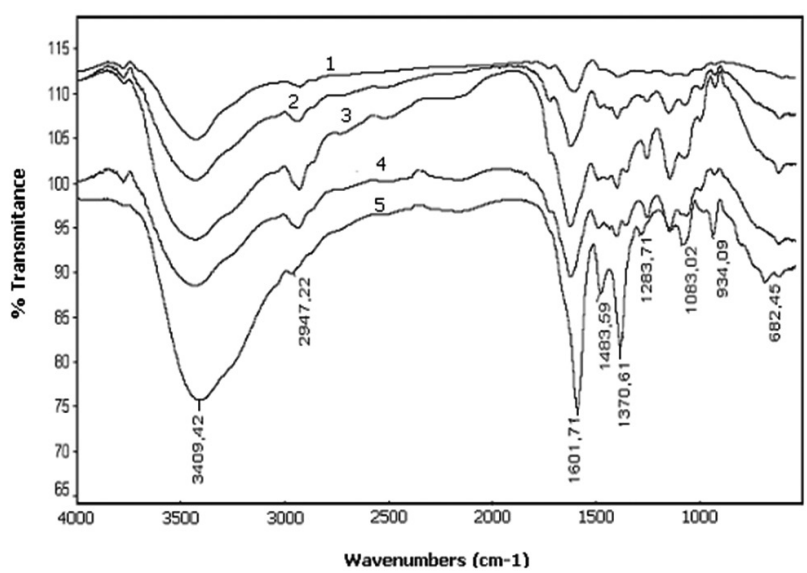

Figure 1. FTIR ( $\mathrm{KBr}$ ) spectra for poly(DMAEA-co-NNDMAAm) 1:1(2); 1:2(4); 2:1(5); and 1:3(3); 3:1(1) / 4 mol-\% MBA.

The primary thermograms of all polymers show a typical sygmoidal shape. All the copolymers degrade in one step and they are stable until $200^{\circ} \mathrm{C}$ with a weight-loss lower than $10 \%$. Polymer 1 shows a different behavior due to, probably the higher content of ester groups which is less stable (see Figure 2).

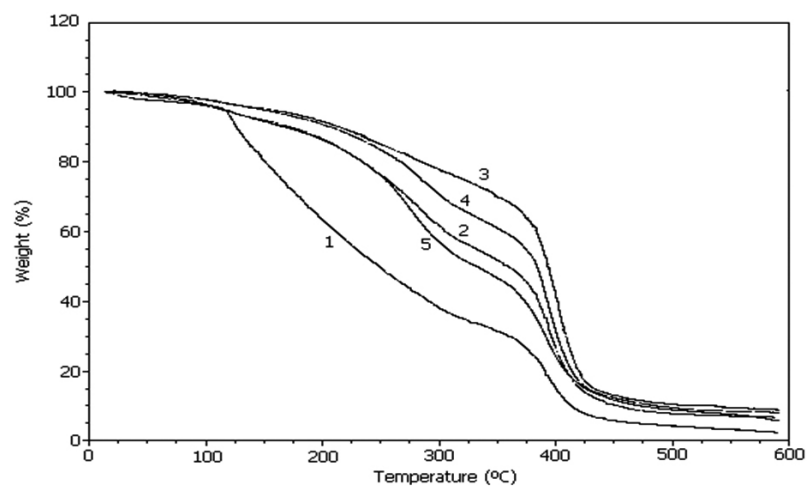

Figure 2. Thermal behavior of poly(DMAEA-co-NNDMAAm) 1:1(2); 1:2(4); $2: 1(5)$; and 1:3(3); $3: 1(1) / 4$ mol-\% MBA, heating rate: $10^{\circ} \mathrm{C} \mathrm{min}^{-1}$ under $\mathrm{N}_{2}$.

The typical scanning electron microscopy (SEM) of poly(DMAEAco-NNDMAAm) 1:2 is shown in Figure 3, where the micrograph does not indicate a porous in the structure.

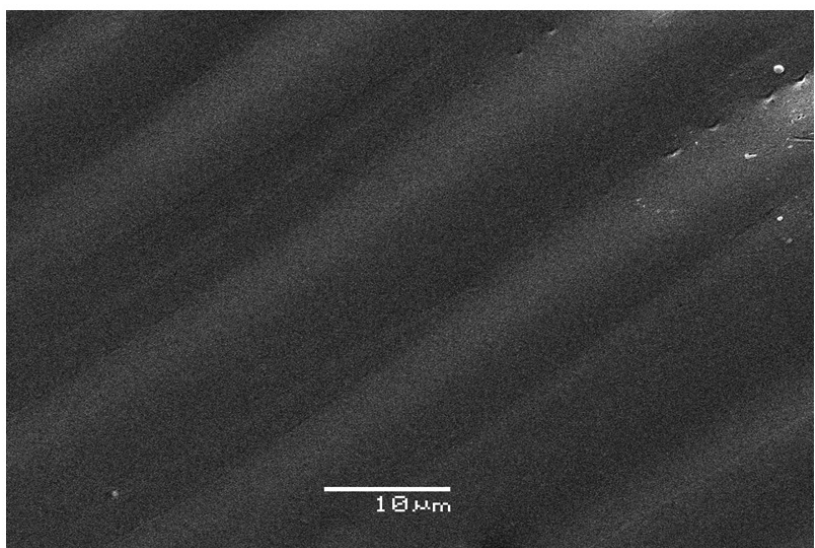

Figure 3. SEM micrographs of poly(DMAEA-co-NNDMAAm) 2:1 / 4 mol-\% MBA (2000x).

Monomer reactivity ratios, (MRR)

The monomer reactivity ratio values for the monomers NNDMAAm and 
DMAEA were determined from the monomer feed ratios and the copolymer composition obtained at relatively low conversions, according to Kelen Tüdös (K-T) method. ${ }^{[24]}$ Copolymer compositions were determined from elemental analysis data (see Table II). To determine the monomer reactivity ratios, a plot of monomer feed composition $\left(\mathrm{M}_{1}\right)$ vs monomer composition in the copolymer $\left(\mathrm{m}_{1}\right)(\mathrm{mol}-\%)$ for DMAEA is shown in Figure 4 for poly(DMAEA-co-NNDMAAm).

Table II. Elemental analysis, N/C relationship, and copolymer composition.

\begin{tabular}{|c|c|c|c|c|c|}
\hline \multirow{2}{*}{ Initial load, M1:M2, (mol/mol) } & & \multicolumn{4}{|c|}{ Found (calculated) value (\%) } \\
\hline M1:M2 & Copolymer $(\mathbf{m 1})$ & Nitrogen & Carbon & Hydrogen & N/C Ratio \\
\hline $3: 1$ & 61.9 & 9.156 & 48.981 & 13.220 & 0.187 \\
\hline & & $\mathbf{1 1 . 0 8 0}$ & $\mathbf{5 9 . 2 7 5}$ & $\mathbf{9 . 1 5 1}$ & $\mathbf{0 . 1 8 7}$ \\
\hline $2: 1$ & 54.3 & 9.432 & 49.225 & 12.735 & 0.192 \\
\hline & & $\mathbf{1 1 . 3 8 2}$ & $\mathbf{5 9 . 4 0 4}$ & $\mathbf{9 . 1 5 1}$ & $\mathbf{0 . 1 9 2}$ \\
\hline $1: 1$ & 37.9 & 10.081 & 49.783 & 12.989 & 0.202 \\
\hline & & $\mathbf{1 2 . 0 9 1}$ & $\mathbf{5 9 . 7 0 8}$ & $\mathbf{9 . 1 5 1}$ & $\mathbf{0 . 2 0 2}$ \\
\hline $1: 2$ & 25.3 & 10.840 & 51.184 & 13.529 & 0.212 \\
\hline & & $\mathbf{1 2 . 7 0 1}$ & $\mathbf{5 9 . 9 6 9}$ & $\mathbf{9 . 1 5 1}$ & $\mathbf{0 . 2 1 2}$ \\
\hline & 18.5 & 11.500 & 52.962 & 12.703 & 0.217 \\
\hline
\end{tabular}

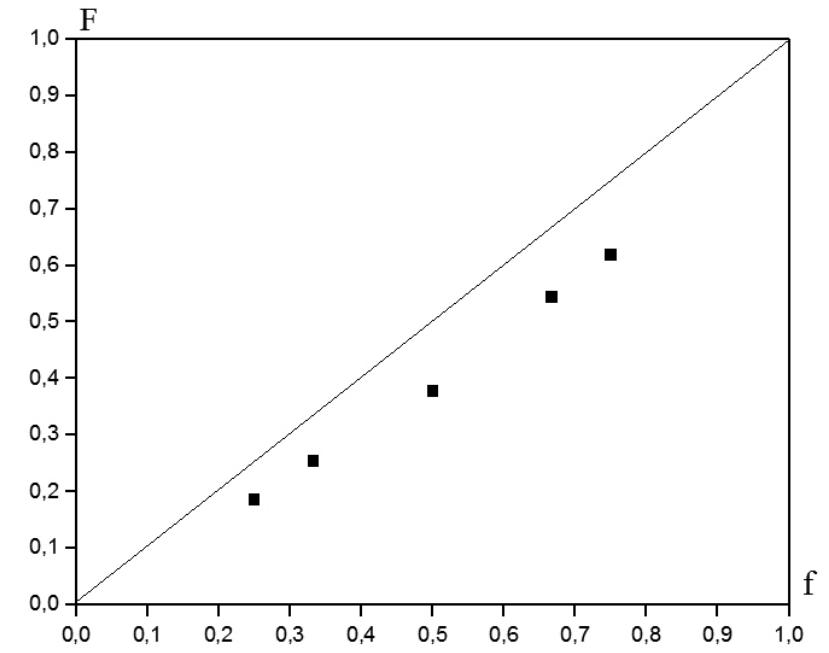

Figure 4. Relationship of $\mathrm{M} 1$ in the feed (M1) and in the copolymer (m1).

The Kelen Tüdös equation (1) is symmetrically transformed into

$$
G=r_{1} \times F-r_{2}
$$

Table III. Reactivity ratios of DMAEA and NNDMAAm in poly(DMAEA-co-NNDMAAm) by Kelen Tüdös for high conversion method, $\mathrm{m}=0.69233552$, $\mathrm{a}=2.67967$.

\begin{tabular}{|c|c|c|c|c|c|c|c|c|c|c|c|}
\hline Charge & Copolym & \multicolumn{2}{|c|}{ conversion } & & & & & & & & \\
\hline M1 $^{(\mathbf{a})}$ & $\mathbf{m 1}^{(\mathbf{b})}$ & $\mathbf{w t}^{\text {(1) }}{ }^{(\mathbf{c})}$ & $\mathbf{X o}$ & $\mathbf{y}$ & $\mathbf{d ~ 1}$ & $\mathbf{d ~ 2}$ & $\mathbf{z}$ & $\mathbf{F}$ & $\mathbf{G}$ & $\mathbf{e}$ & $\mathbf{h}$ \\
\hline 75.0 & 61.9 & 46.5 & 3.000 & 1.625 & 0.401 & 0.740 & 0.380 & 11.252 & 1.644 & 0.8077 & 0.1180 \\
\hline 66.7 & 54.3 & 49.5 & 2.000 & 1.188 & 0.421 & 0.708 & 0.443 & 6.047 & 0.425 & 0.6929 & 0.0486 \\
\hline 50.0 & 37.8 & 46.3 & 1.000 & 0.608 & 0.366 & 0.602 & 0.494 & 2.487 & -0.794 & 0.4814 & -0.1536 \\
\hline 33.3 & 25.3 & 47.2 & 0.500 & 0.339 & 0.370 & 0.546 & 0.585 & 0.990 & -1.131 & 0.2699 & -0.3081 \\
\hline 25.0 & 18.5 & 46.3 & 0.333 & 0.227 & 0.352 & 0.517 & 0.596 & 0.638 & -1.296 & 0.1923 & -0.3906 \\
\hline
\end{tabular}




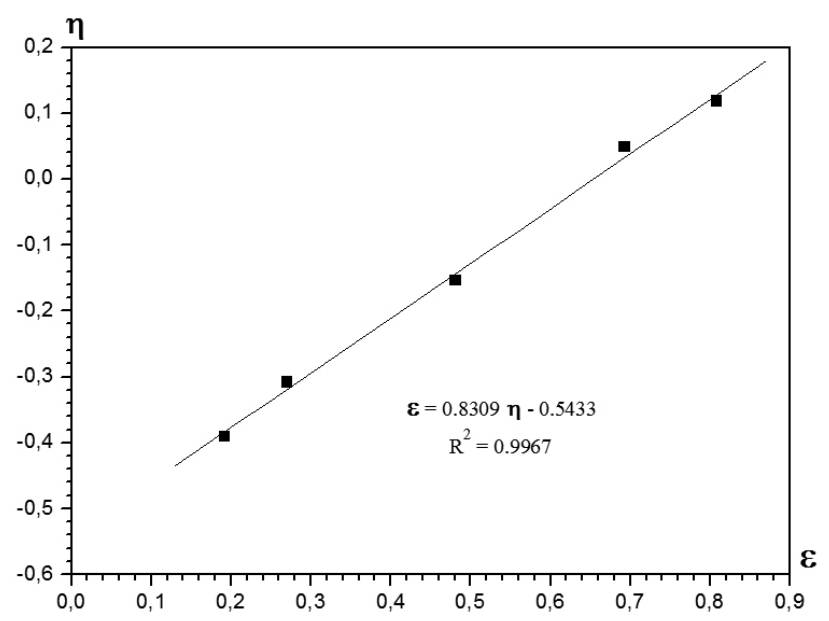

Figure 5. h vs $x$ representation of the copolymerization parameters of poly(DMAEA-co-NNDMAAm) by K-T method.

According to these values, the monomer reactivity ratios for poly(AA-coNNDMAAm) are the following: $r_{1}=0.288$ and $r_{2}=1.460,\left(r_{1} \times r_{2}=0.419\right)$. According to the results from the data, these copolymers would correspond to copolymers in random mainly.

These results suggest for poly(DMAEA-co-NNDMAAm) system, that the chain growth reactions proceeds predominantly by the addition of DMAEA monomer to the $\sim$ R-NNDMAAm macroradical, which NNDMAAm possess a higher tendency of homopropagation to the chain producing also copolymers in random

Low Critical Solution Temperature (LCST)

It is found that aqueous solutions of these copolymers exhibited a lower critical solution temperature (LCST), depending on their chemical composition, followed by coacervate formation above the LCST. Furthermore, thermosensitive hydrogels could be prepared by the free radical copolymerization of DMAEA and NNDMAAm in the presence of the crosslinking reagent MBA and initiator PSA.

LCST was determined by DSC and this temperature was determined at the point of the first slope where was starting the release of water from the hydrated hydrogel.

Poly(DMAEA-co-NNDMAAm) showed a LCST around $78^{\circ} \mathrm{C}$, which was significantly higher than that poly(NIPAAm) (23). With an increase of hydrophilic DMAEA moiety in the copolymer, the LSCT increased, see copolymers with initial feed composition 2:1 and 1:2 respectively, (see Figure 6). The LCST of copolymers comprising NIPAAm and other acrylamide derivatives have been reported to be between 0 and $65^{\circ} \mathrm{C}$, and it is dependent on the hydrophobic-hydrophilic balance of their copolymers.

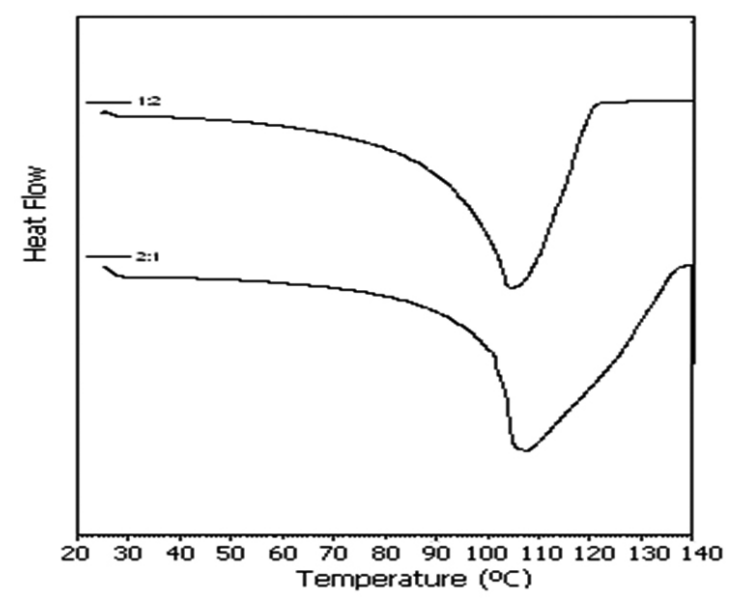

Figure 6. DSC thermograms of poly(DMAEA-co-NNDMAAm) show a LCST around $78{ }^{\circ} \mathrm{C}$ for a feed composition $2: 1$ and $57.6{ }^{\circ} \mathrm{C}$ for a ratio $1: 2$. Heating rate: $10^{\circ} \mathrm{C} / \mathrm{min}$.

\section{Absorbency}

The absorbency of hydrogels in distilled water and ethanol for five feed mol ratios are shown in Figure 7. It is shown that the highest value is obtained with a polymer containing a ratio $2: 1$. This result is due to the gradual diffusion of water molecules into the network of the hydrogel and complete filling or occupation of the pre-existing or dynamically formed spaces in the polymer chains. The results with ethanol are included in order to compare with water, both highly hydrophilic.

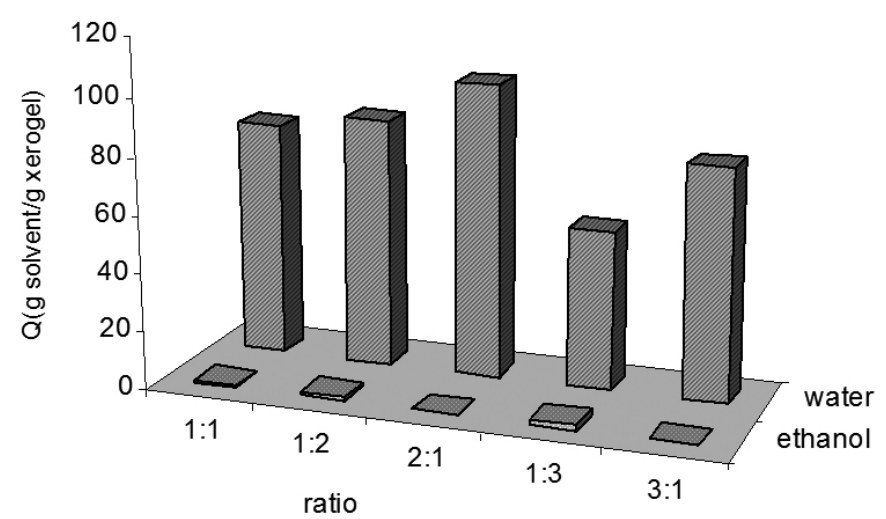

Figure 7. Absorption (Q) of poly(DMAEA-co-NNDMAAm) $1: 1 ; 1: 2$ $; 2: 1 ; 1: 3 ; 3: 1 / 4$ mol \% MBA in twice-distilled water and ethanol at room temperature.

Equilibrium swelling in water and ethanol of the ratio 2:1 at room temperature as a function of percent of MBA is shown in Figure 8.

The absorbency of poly(DMAEA-co-NNDMAAm) $2: 1$ with 2 mol- $\%$ of MBA copolymer is higher than that other copolymers in twice-distilled water at room temperature. It is due to the higher amount of amine groups incorporated into the backbone. These strong amine groups adsorb significantly water molecules. In ethanol was not observed absorption.

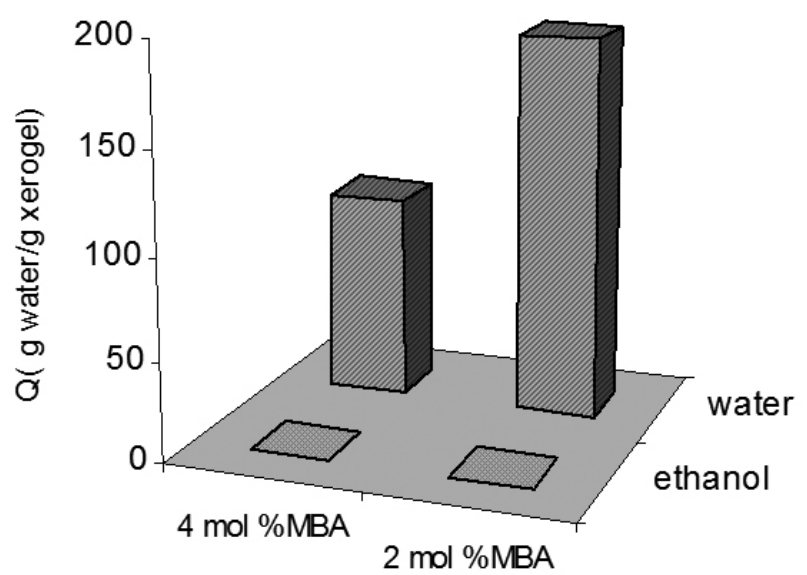

Figura 8. Absorption (Q) of poly(DMAEA-co-NNDMAAm) corresponding to the ratio $2: 1 /$ with 4 mol- $\%$ and 2 mol- $\%$ of MBA in twicedistilled water and ethanol at room temperature.

Effect of pH on absorbency

To investigate the influence of $\mathrm{pH}$ on the degree of gel swelling, the $\mathrm{pH}$ was adjusted with $1 \mathrm{M} \mathrm{HCl}$ or $1 \mathrm{M} \mathrm{NaOH}$ from $\mathrm{pH} 1$ to $\mathrm{pH} 9$. Figure 9 shows the effects of the solution $\mathrm{pH}$ values on the swelling behavior for all the studied copolymers. The water absorption curve shows an optimal value at $\mathrm{pH} 5$ when the feed monomer ratio is $2: 1$ with $2 \mathrm{~mol}-\%$ and $4 \mathrm{~mol}-\%$ of MBA. At $\mathrm{pH}$ above 9 , poly(DMAEA-co-NNDMAAm) maintains a high absorption capacity in the solution with a high basic concentration. 


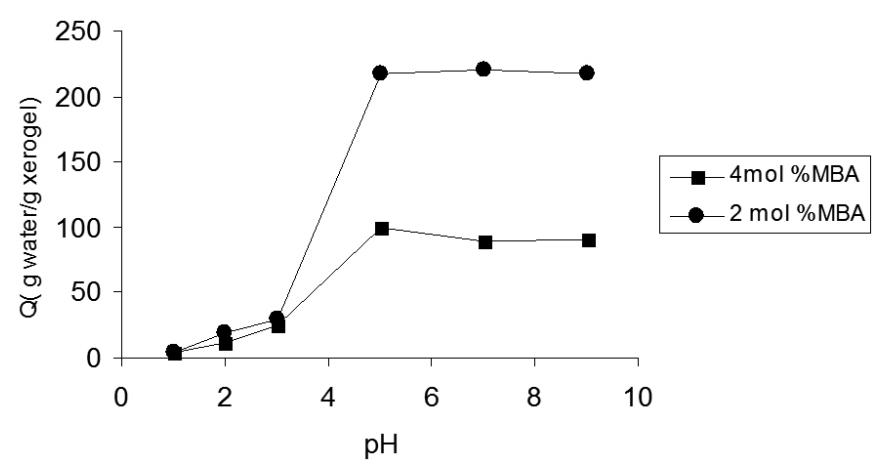

Figure 9. Absorption (Q) of poly (DMAEA-co-NNDMAAm) ratio 2:1 / 4 and 2 mol- $\%$ MBA in water at room temperature for $\mathrm{pH} 1,3,5,7$, and 9.

Effect of the temperature on absorbency

The effect of the temperature on the absorbency for poly(DMAEA-coNNDMAAm) for 2:1 feed mol ratios is shown in Figure 10. This study was carried out with a contact time of $1 \mathrm{~h}$ for each temperature. It demonstrates that the absorbency does not change significantly as increases the temperature until $45^{\circ} \mathrm{C}$ and then increase sharply for ratio $2: 1$ with 2 mol- $\%$ of MBA; but ratio 2:1 with 4 mol-\% MBA maintaining constant.

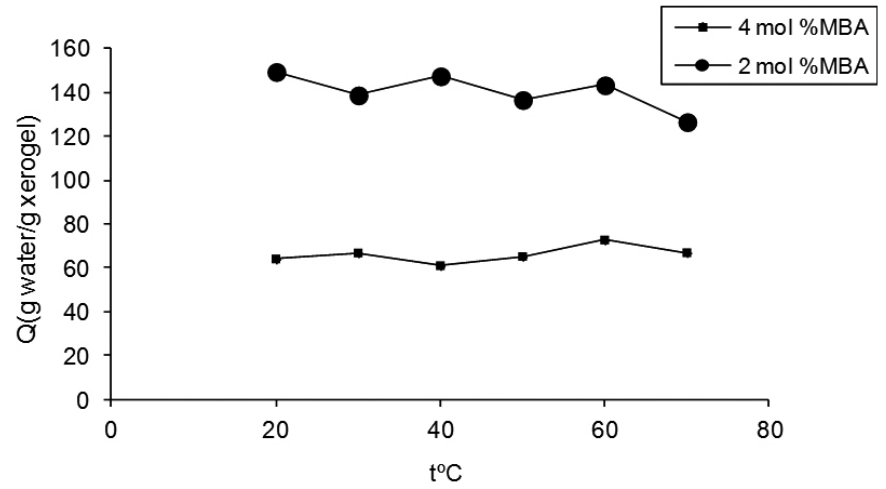

Figure 10. Absorption (Q) of poly(DMAEA-co-NNDMAAm) ratio 2:1/ 4 and 2 mol- $\%$ MBA at different temperatures.

Effect of the temperature on the maximum swelling degree

Figure 11 shows that the swelling degree decreases as the temperature increases for the three gels, and it is a characteristic behavior. At a higher temperature, the coil is contracted limiting the entrance of water in to the diffusion system.

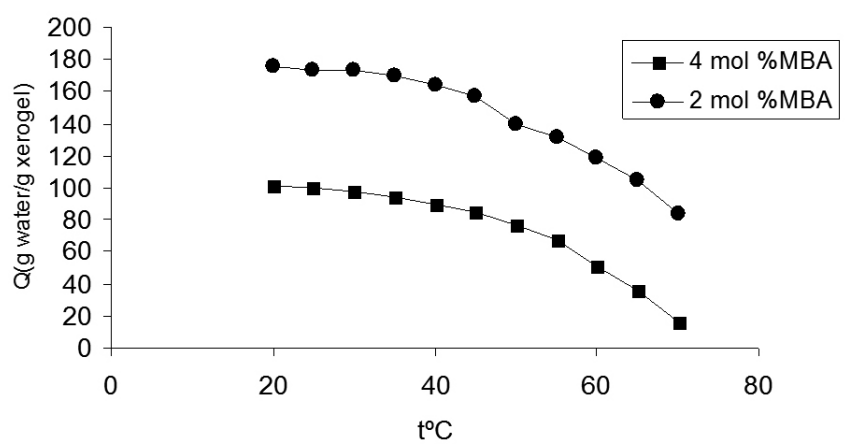

Figure 11. Water loss (Q) of poly(DMAEA-co-NNDMAAm) ratio 2:1 / 4 and 2 mol- $\% \mathrm{MBA}$ at different temperatures for 24 hours.

Effect of $\mathrm{NaCl}$ solutions on absorbency

Figure 12 shows the effect of the solution's salt concentrations $(\mathrm{NaCl})$ on the absorbency of the poly(DMAEA-co-NNDMAAm). The results indicate that the absorbency of this polymer decreases with an increase in the concentration of the univalent salt solution at three different initial mol ratios. Additionally, the effects of ion hydration are remarkable at the lower ionic concentration $(0.2$ $\mathrm{mol} / \mathrm{L})$ and weak at the higher ionic concentration $(0.4 \mathrm{~mol} / \mathrm{L})$.

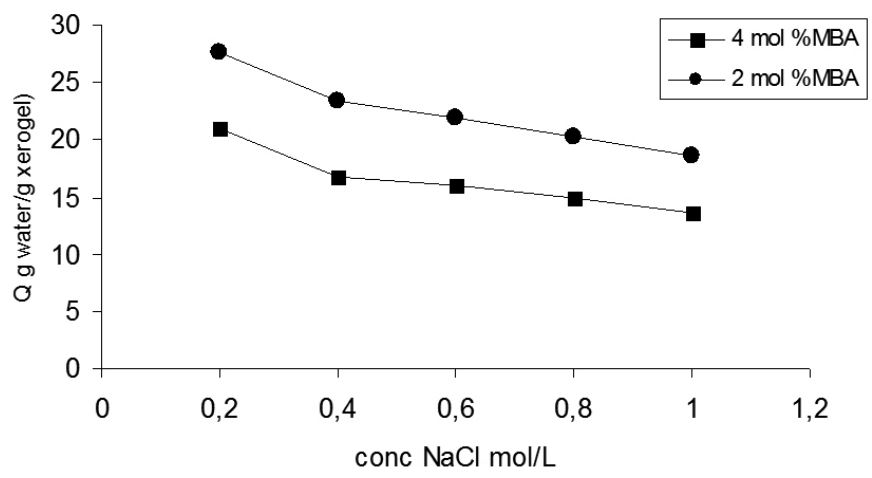

Figure 12. Absorption (Q) of two polymers, poly(DMAEA-coNNDMAAm) ratio 2:1 / $4 \mathrm{~mol} \%$ and $2 \mathrm{~mol}-\% \mathrm{MBA}$ at room temperature from different concentrations of $\mathrm{NaCl}$.

\section{CONCLUSIONS}

A novel hydrogel of DMAEA and NNDMAAm was prepared in aqueous solution, and the swelling properties were studied. The experimental results show that poly(DMAEA-co-NNDMAAm) has a high absorbency not only in water but also in ethanol and salt solutions. The absorbency of these polymers decreased as the solvent's polarity decreased.

The effect of $\mathrm{pH}$ on the absorbency was studied. It was found that the absorbency of poly(DMAEA-co-NNDMAAm) 2:1 increased as the $\mathrm{pH}$ increased from 1 to 5 . It was maintained practically constant from this $\mathrm{pH}$ to $\mathrm{pH}$ 9. It was found that the absorbency increased until $50^{\circ} \mathrm{C}$ for the copolymer more cross-linked, and then kept constant up to $70^{\circ} \mathrm{C}$. This result implies that poly(DMAEA-co-NNDMAAm) can be used in a wide temperature range. The influence of the salt solutions on the absorbency was investigated, and the results indicate that absorbency is a decreasing function of the rising salt concentration.

\section{ACKNOWLEDGEMENTS}

The authors thank the FONDECYT (Grant No 1050572) and PIA (Anillo ACT-130) for financial support.

\section{REFERENCES}

1. H. El Sayed, R.C. Kirkwood, N.B.Graham, J. Exp. Bot. 42, 891 (1991)

2. W.F. Lee, W.H. Chiang, J. Appl. Polym. Sci. 91, 2135 (2004)

3. M.M. Ozemed, O. Okay, Polym. Bull. 52, 83 (2004)

4. E. Jabbari, S. Karbasi, J. Appl. Polym. Sci. 91, 2862 (2004)

5. D.M. Devine, C.L. Higginbotham, Eur. Polym. J. 41, 1272 (2004)

6. J. Jovanovic, B. Adnadjevic, Polym. Bull. 58, 243 (2007)

7. J.L.Escobar, D.M. García, D.Zaldivar, I. Katime, Revista Iberoamericana Polímeros 3,3,(2002)

8. F.M. Goycoolea, W.M.Argüelles-Monal, J. Lizardia, C. Peniche, A. Heras, G. Galed, E.I. Díaz, Polym. Bull. 58, 225 (2007)

9. V. Sáez, E. Hernáez, L.S. Angulo, Revista Iberoamericana de Polímeros 5, 1 (2004)

10. B. Rojas de Gáscue, R. Aguilera, J.L. Prin, H. Cequea, J. Cumana, E. Rosales, M. Ramírez, Revista Iberoamericana de Polímeros 5, 1 (2004)

11. B. Rojas de Gascue, Ramírez M, R. Aguilera, J.L. Prin, C. Torres, Revista Iberoamericana de Polímeros 7, 3 (2006)

12. N. Orakdogen, O. Okay, Polym. Bull. 57, 631 (2006)

13. S. L. Tomic, E.H. Suljovrujic,Y. M. Filipovic, Polym. Bull. 57, 691 (2006)

14. H. Kasgoz, I. Aydin, A. Kasgoz, Polym. Bull. 54, 387 (2005)

15. O.B- Uzum, S. Kundakci, E. Karadag, Polym. Bull. 57, 703 (2006)

16. P.V. Dadhaniya, M.P- Patel, R.G. Pate, Polym. Bull. 57, 21 (2006)

17. M. Solener, E. Uguzdogan, M. Nurbas, T. Camli, O.S. Kabasakal, S. Patir, A. Tuncel, Polym. Bull. 57, 341 (2006)

11. X. Ma, Y. Xing, Polym. Bull. 57, 207 (2006) 
12. A.Ozdagan, O. Okay, Polym. Bull. 54, 435 (2005)

13. K. Pagonis, G. Bokias, Polym. Bull. 58, 289 (2007)

14. S.Çavuş, G. Gürdağ, Polym. Bull. 58, 235 (2007)

22. Ch. Xu, Kopeček J. Polym. Bull. 58, 53 (2007)

15. G.S. Chauhan, S. Chauhan, K. Chauhan, U. Sen, J. Appl. Polym. Sci. 99, $3040(2006)$

16. F. Tüdös, T. Kelen, B. Turcsanyi, J. Polym. Sci.: Polym. Chem. Ed. 19, 1119 (1981)

17. H.D. Schild, Progr. Polym. Sci. 17, 163 (1992)

18. M. Shibayama, T. Tanaka, Adv. Polym. Sci. 109, 1 (1993)

19. C.Wu, Polymer 39, 4609 (1998)

20. M. Hahn, E. Görnitz, H. Dautzenberg, Macromolecules 31, 5616 (1999)

21. D Kuckling, H.J.Adler, L.Ling, W.D. Habicher, K.F.Arndt, Macromol. Chem. Phys., 201, 273 (2000)

22. Y. Liu, J.L. Velada, M.B. Huglin, Polymer 40, 4299 (1999)
23. D.Kuckling, H.J. Adler, L. Ling, W.D. Habicher, K.F. Arndt, Polym. Bull. 44, 269 (2000)

24. C. Wu, S. Zhou, Macromolecules 28, 8381 (1995)

25. G. Chen, A.S. Hoffman, Macromol. Chem. Phys. 196, 1251 (1995)

26. M. Shibayama, Y. Suetoh, S. Nomura, Macromolecules 29, 6966 (1996)

27. L.M. Geever, D.M. Devine, M.J. Nugent, J.E. Kennedy, J.G. Lyons, C.L. Higginbotham, Eur. Polym. J. 42, 69 (2004)

28. W.S. Ali, S.A. Zaidi, J. Appl. Polym. Sci. 98, 1927 (2005)

37. T.Tanaka Phys. Rev. Let. T. 40, 820 (1978)

29. M. Jeria, G. del C. Pizarro, O. Marambio, M. Huerta, P. Valencia, B.L. Rivas, J. Appl. Polym. Sci. 98,1897 (2005)

30. S.A. Pooley, B.L. Rivas, F.J. Riquelme, J. Chil. Chem. Soc. 52, 1, 1088 (2007)

31. S.A. Pooley, B.L. Rivas, A. Cárcamo, G. del C. Pizarro, J. Chil. Chem. Soc. 53, 1483 (2008) 